\title{
UNDERSTANDING TRADITIONAL ANTI-SEISMIC STRATEGIES BEYOND THEIR DISAPPEARANCE AND DISTORTIONS: YAZD QAJAR ARCHITECTURE CASE STUDY
}

\author{
EUGÉNIE CRÉTÉ ${ }^{1 *}$, SANTOSH YADAV ${ }^{2}$, NARIMAN FARAHZA ${ }^{3}$, LUIS ARLEO ${ }^{1}$, \\ MAJID HAJMIRBABA ${ }^{1}$, YANNICK SIEFFERT ${ }^{2}$ AND PHILIPPE GARNIER ${ }^{1}$ \\ ${ }^{1}$ CRAterre laboratory, Architecture, Environnement et Cultures Constructives research unit \\ Ecole Nationale Supérieure d'Architecture de Grenoble \\ 60 av. de Constrantine, 38000 Grenoble, France \\ e-mail: crete.eugenie@gmail.com \\ (*corresponding author) \\ ${ }^{2}$ Univ. Grenoble Alpes, CNRS, Grenoble INP, 3SR, 38000 Grenoble, France \\ ${ }^{3}$ Earthen Architecture department of the Vernacular Architecture Research Center (VARC), Art and \\ Architecture Faculty, Yazd university, Iran
}

Keywords: traditional seismic strategies, Qajar architecture, earthen heritage, Yazd, Iran

\begin{abstract}
Understanding traditional seismic strategies is necessary to conduct appropriate restoration of historic buildings and city centers located in earthquake-prone areas. But, the fast disappearance of vernacular built heritage and of the associated popular knowledge and know-how, along with the spread of inappropriate maintenance works, make it very difficult. To overcome these obstacles, it is suggested to broaden the scope of observations by including both larger geographical areas and elements that do not appear as seismic features at first consideration. This paper illustrates the relevance and the limits of this approach by applying it to the case study of Yazd historic city center. Yazd is located in a moderate seismic area and is famous for its well-preserved historic city center, with a high number of Qajar adobe buildings in various conditions. The authors combined literature review, direct observation of numerous buildings and a deeper study of four Qajar houses to conduct the first part of their research. The data collected mainly relates to the geometrical features, the materials used and the interconnections between elements at different scales. Their analyses led to the elaboration of several assumptions on the seismic behaviour of the studied adobe buildings and vaults and on the distortions some features may have suffered. To validate these assumptions, two methodologies were used. Both are illustrated in this paper through the study of the insertion of baked bricks in adobe vaults. The first one is based on observation campaigns on damaged houses. The second one is based on experimental works, with tests conducted on the shear strengths of masonry made with mud mortars and adobes or baked bricks to better understand how builders benefited from mixing these materials in an adobe vault. Finally, the authors discuss the limits of the method and the extent to which restoration projects can benefit from it.
\end{abstract}




\section{INTRODUCTION}

Earthen historic buildings are usually associated to features improving their behaviour in case of dynamic solicitations, amongst others in case of earthquakes. Most of them are not endorsed by official seismic codes that currently apply in numerous countries. Those codes are based on the technical knowledge that was recognized at the time of their redactions which is mostly after the Second World War. At that time, engineers and institutions were focusing on modern materials such as steel and concrete and the strategies associated with them. The absence of research on traditional technics and materials, and more particularly on their aspects related to seismic engineering, induced a lack of academic knowledge that makes their efficiency difficult to calculate or digitally assess. Yet, the precision and the amount of recognized information related to a technic often take precedence over its effective performance when judging it [1]. The efficiency of a traditional technic can be assessed by post-earthquake observation. This kind of analyses and learning processes were part of builders capacity building in most seismic areas until the end of 19th century [1] but was neglected ever since in favor of calculation and digital analysis. Post-earthquake observations and empirical assessments are nowadays facing three main interlocked hindrances: postearthquake quick destruction of vernacular heritage by the institutions in charge of rebuilding, the distortion of traditional technics induced by previous loss of knowledge, and the destructions due to unsuitable previous maintenance of built heritage [2,3]. Hence, the characterizations of traditional seismic strategies are often long and complex, which turns out

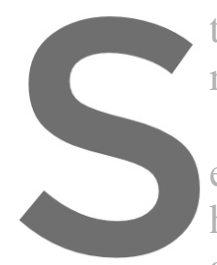
to be a major issue as it is often a necessary step to conduct an
restoration of historic buildings.
To what extent can researchers overcome these disappeara
extension of observations to broader geographical areas, not rest
helping? And what about including in the characterization rese appear as anti-seismic features at first consideration? To

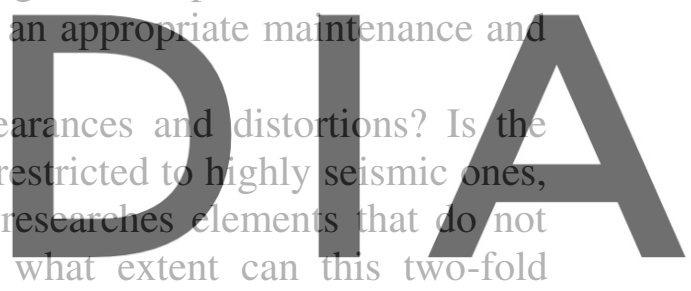
broadening feed the elaboration of technical assumptions that can later be assessed by

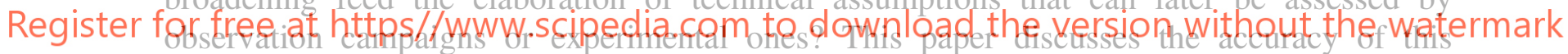
approach by applying it to the case study of Yazd city center and more specifically to the insertion of baked bricks in adobe vauits.

Yazd is a city in the desert part of Iran that is famous for its well preserved historic city center. Most of its historic buildings were heavily modified during its latest prosperous period (18th century) and until the middle of the 19th century (Qajar period) [4]. Yazd historic city center is a dense area where traditional buildings are mainly made out of adobes [5]. They are closely interlocked: Lateral thrusts that result from vaults and domes are balanced on scales that range from inside a single house to inside an urban block and up to in-between blocks, thanks to arches and vaults crossing the streets. Traditional buildings usually have one or two levels above the ground and up to three underground levels. Iran is located in a highly seismic zone, and earthquakes in Yazd are numerous and of low magnitudes. An acceleration of $0.25 \mathrm{~g}$ (associated to a return time of 475 years) is to be taken into account when building in Yazd, according to Iranian seismic design code [6].

\section{METHODOLOGY}

In order to overcome the difficulties linked to the understanding of traditional anti-seismic 
strategies through direct post-earthquake observations, the authors suggest a two-step methodology that is detailed below. First step consists in developping technical assumptions on traditional anti-seismic features by broadenning the scope of observations at two levels: first, a geographical broadening, and second, a technical broadening. Then, the technical assumptions resulting from these observations are assessed through different methods designed on a case-by-case basis. This methodology was applied to study traditional seismic technics related to Qajar architecture, as illustrated in this paper.

\subsection{Geographical broadening}

The suggested geographical broadening consists in studying anti-seismic architectural features without restricting the observations to highly seismic areas. This is based on the following argumentation: A local seismic building culture is likely to develop in locations where earthquakes are frequent enough with intensities that are medium enough to allow for feedbacks [3]. These local seismic cultures then often spread into less seismic areas, facing more or less distortions [1]. Earthquakes in Yazd are numerous but of too low intensities to stir up the development of a specific seismic culture. But building cultures in Yazd were fed by those of the surrounding areas - that face earthquakes of higher intensities - with possibilities of distortions that must be kept in mind while conducting the analyses.

Yazd historic city center is very instructive thanks to its high number of Qajar buildings and their various conditions. Though many houses are built inwards, around a central courtyard, the collapsing of numerous-external walls makes it easy to have an understanding of several architectura complement these then Architecture of Yazd a and Nikbin houses. The materials used and
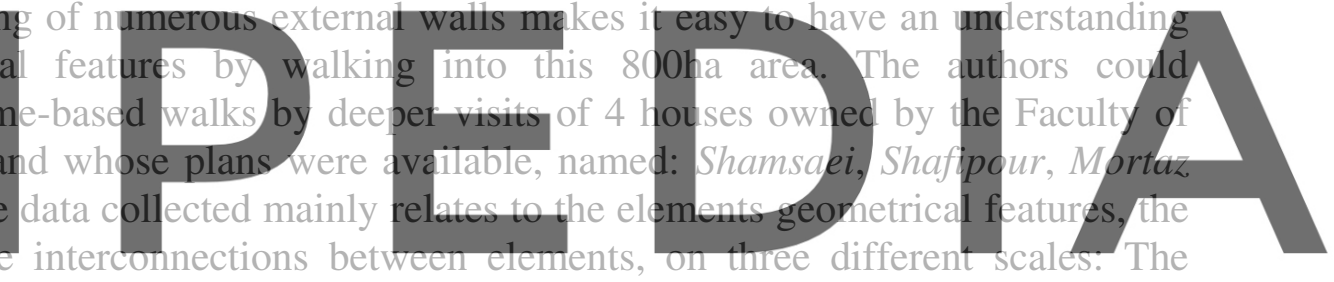
largest one relates to the house itself and its block; the second one to the walls; and the

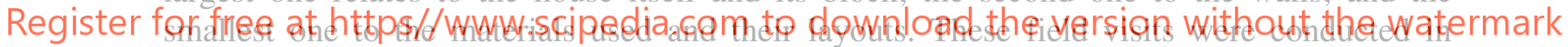
December 2015 and January 2016.

\subsection{Technical broadening}

Numerical modellings usually are of low accuracy to conduct seismic assessments of adobe historic buildings as they do not assess properly traditional materials and connections especially when subject to dynamic solicitations - by lack of knowledge or to avoid unmanageable complexity induced by advanced nonlinear analyses [1,7,8]. Though innovative modelling may help in better understanding adobe buildings behaviour [9], geometrical considerations still are of major interest to conduct a first assessment. An analysis of Qajar buildings was conducted considering usual earthquake-resistant guidelines of masonry buildings, a simplified method for the estimation of the resonant period of buildings [10], and several indexes proposed by Lourenço et al [11] and used by Sadeghi et al [8] to assess numerous Yazdi buildings. Moreover, the analysis included studies on the stiffness of the different elements and their connections [12], on the collapsing mechanisms of vaults [13], and on the energy dissipation due to friction in the connections between structural elements [14]. Besides, research works conducted on earthen building materials helped 
understanding mud mortars characteristics and the importance of friction in the seismic behaviour of adobe buildings $[15,16]$.

The technical broadening suggested as part of the methodology was conducted after this first analysis of Qajar buildings seismic behaviour based on usual technical considerations. It consists in a second analysis including elements of Qajar architecture that did not appear as anti-seismic at first consideration. Indeed, the loss of knowledge and the distortion of some traditional anti-seismic strategies that inexorably results from it prevent from identifying (and understanding) them easily. The main challenge is then to identify if they could be the remains of any forgotten anti-seismic strategy and to what extent they have been distorted. To conduct this technical broadening, it is necessary to get familiar with the wide scope of traditional anti-seismic technics and practices that developed in various locations. A collection of examples resulting from 10 years of field observations by CRAterre and its partners helps in getting this wider understanding of seismic strategies through the study of traditional monumental and vernacular architecture [17]. Applying this method on Yazdi built heritage requires a global knowledge of Qajar architecture beyond structural features [18] and of its assumed vulnerability $[5,8,19]$ in relation with Yazd seismic activity [6].

\subsection{Consolidating the induced technical assumptions}

In order to illustrate the second step of the methodology - the consolidation of the technical assumptions resulting from step 1 - the authors selected one of their technical assumptions and consolidated it thanks to two different methods. First, by observations collapsing structures, solicitations of similar observations of collapsin study, the authors resistances provided
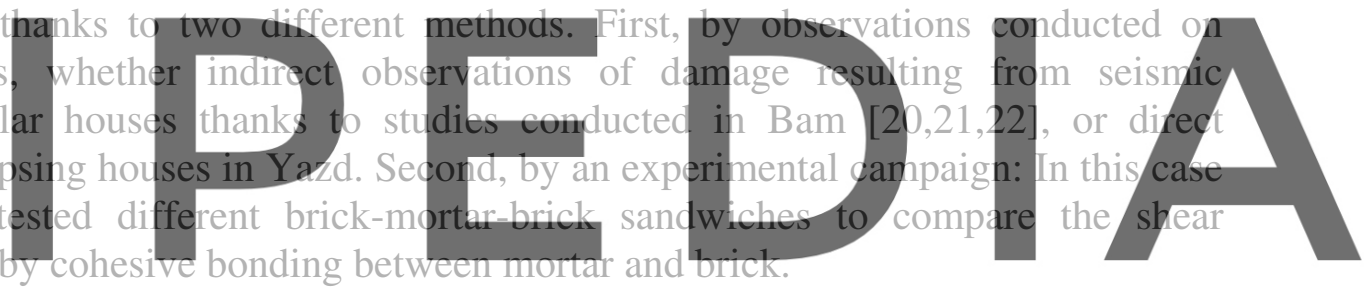

Register for firestat thestps//www.scipedia.com to download the version without the watermark

\subsection{The elaboration of technical assumptions related to traditional anti-seismic features} of Yazdi Qajar architecture

Yazdi Qajar architecture presents a lot of strengths regarding its seismic behaviour. The global shape, mass and rigidity of most Qajar houses in Yazd reduce the risks of resonance between the building and the ground in case of an earthquake: buildings resonant period was estimated to $0.1 \mathrm{~s}$ using the equation developped in the Argentinian seismic code [10]. This equation results in a rough approximation as it relies on a basic oscillator model and do not take into account several influencing elements (including the foundations type, the number and spacing of the building levels, the ground nature and the mechanical coupling of the building and the ground), which could result in an error of up to 50\% [10]. It is to compare with Yazd ground periods that was estimated between $0.2 \mathrm{~s}$ and $0.5 \mathrm{~s}$ thanks to Eurocode 8 and local geological data [23]. Moreover, most Qajar houses include one or several courtyards. These are typical local open spaces that are often used as a living space during seismic episode in different cultures, with testimonies of this practice in Northern Iran [19]. Yazdi houses are built inside a boundary wall with an almost rectangular shape and very few 
openings. Inside this surrounding wall, rooms are built with a highly symmetrical pattern. Besides, an important part of the rooms are built underground and around a massive soil core that is the ground under the courtyard: the basement stiffness is thus so high that the ground motions are transferred to the first floor without amplification. Those three points result in a stiffness distribution of the construction that greatly reduces risks of walls distortion in case of an earthquake.

Focusing on Nikbin house, the authors calculated different indexes that can help in assessing the sizing of the walls. First, the load analysis resulted in an estimation of static loads of $0.15 \mathrm{MPa}$, that is more than ten time lower than the estimated ultimate compression resistance of the adobe masonry [24]. This oversizing is usual in traditional masonry structures and allows for important dynamic load to apply without endangering the structure [3]. Moreover, the authors estimated the area of walls that would resist shear stresses in case of a quake by calculating its density value, that is defined as the ratio between the total shear walls sectional area and the floor area. Eurocode 8 recommends a minimum density value of $10 \%$ in seismic zones where predictable ground acceleration is above $0.2 \mathrm{~g}$, which is the case in Yazd [6]. This value has been estimated to $15 \%$ in both principal directions. Moreover, it is interesting to compare the shear walls sectional area - that is related to their resistance to shear stress - to the building weight - that is related to the shear stress the whole building will have to resist. This indicator was estimated to $5 \mathrm{~m}^{2} / \mathrm{MN}$, which is one more time far above the minimum recommended value in highly seismic zone $\left(2.5 \mathrm{~m}^{2} / \mathrm{MN}\right)$ [11]. This means that its walls should theoretically resist the compression and shear stresses that would be induced by an earthquake before collapsing, with a high safety margin.
Going beyond these general considgrations, several technical assumptions were elaborated
relating to the seismic behaviour of different architectural iterns thanks to the observation
campaigns conducted on Yazdi Qajar houses.
A first assumption relates to the smaller vaults that are built above the haunches of many vaults. A vault stability is compromised mainly by the inertial forces due to its own materials,

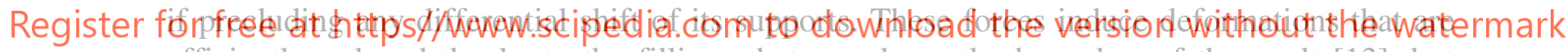
efficiently reduced thanks to the fillings that are above the haunches of the vault [13], but these fillings increase the weight of the roofing. In Yazdi architecture, the haunches of the vaults are often not strengthened by fillings but by smaller vaults named kane poush, that are either perpendicular to or with the same axis as the main one (Figure 1). These smaller vaults are usually explained by their thermal and execution efficiency, but they are also probably of high importance to increase the resistance of the main vault without burdening it.

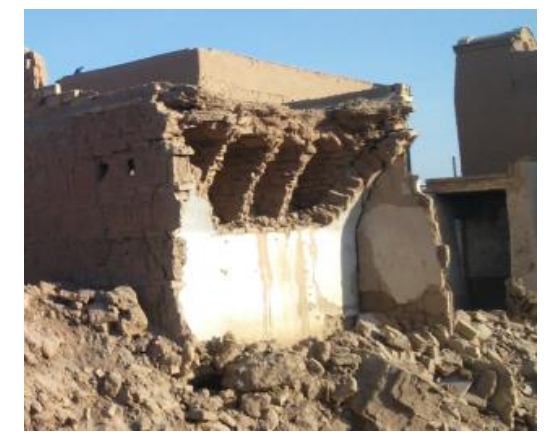

Figure 1: An example of kane poush filling the haunches of a collapsed vault, Yazd (Crété, 2015) 
A second example relates to the wooden and glass façade that often closes winter living spaces in traditional Qajar houses. Gable-end walls are often the first to collapse in case of an earthquake: they are usually slightly linked to the rest of the structure and have a high slenderness ratio. Gable-end walls that were not rigid enough have turned disastrous during Bam earthquake [20]. Closing those spaces with a light and flexible item is not only allowing for large amount of light to enter, it also contributes to avoiding the collapse of heavy walls in case of out-of-plan quake.

A third example relates to the layout of masonry infill panels and seems to be a variation of a well-known seismic principle of framed structure: masonry infill walls should be weaker than the load-bearing structure as it should fail first in case of too high solicitations [12]. In Yazd, most infill panels are built with specific layouts that have an obvious aesthetic aim. But they are also probably less rigid than common masonry layout. Moreover, cracks can propagate easily through the pattern but by dividing the panel in elements that keep interlocked thanks to their geometry (Figure 2). From a structural point of view, it is hence probably very interesting to use them as infill of load-bearing structures.
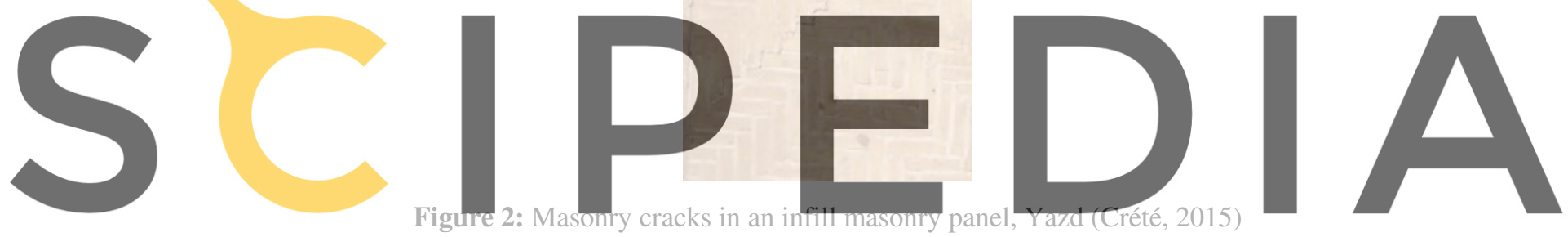

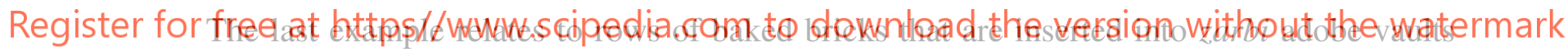
(barrel vaulting), approximately every $50 \mathrm{~cm}$, and that may be part of a strategy to improve the global stability of adobe vaults. In case of heterogeneous composition of masonry structure, the mortar joint acts as a weak plane from where the failure occurs [25]. In case the interface between the baked brick and the mud mortar is weaker than the one between the adobe and the mud mortar, this technic can be understood as a way to create fuse interfaces and facilitate the creation of sectional cracks during a quake (thus preventing diagonal cracks that would endanger the structure). The formation of cracks and the local shifts that occur at those interfaces are often very efficient to dissipate the energy the building caught during the quake [14].

Finally, it may happen that traditional seismic features have face such distortions that they do not contribute anymore to improving the building's earthquake behaviour. For example, alcoves are a major aesthetical element of Yazdi traditional architecture (Figure 3) [18]. But they should not be reduced to their aesthetical function in a seismic context: First, because they can allow for storing items without risking cupboard overturning. Second, because they are the negative of buttresses that increase the wall stability with a limited amount of material. But the size of many alcoves and the way they were built make it difficult to keep in mind 
those technical advantages, as they have often been reduced to a dozen cm deep and made out of plasters, or are no longer structurally linked to the walls.

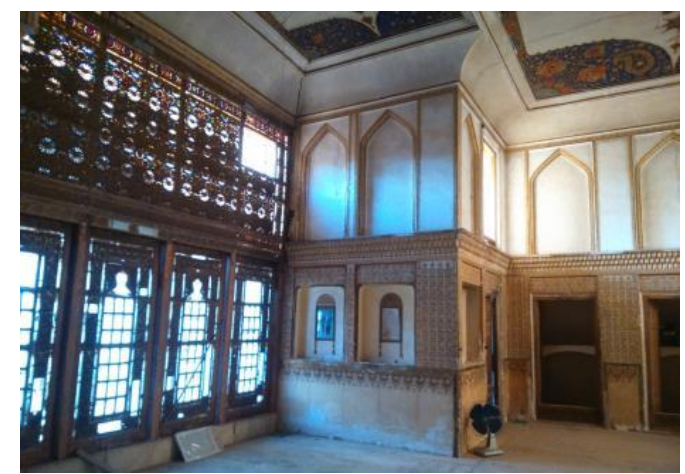

Figure 3: Different kind of alcoves in Shafipour house, Yazd (Crété, 2015)

\subsection{A deeper study of the baked brick insertions in adobe vaults}

The broadening of observations enabled the authors to elaborate several technical assumptions regarding architectural features typical of Qajar architecture that were probably developed as part of a local seismic culture. The authors selected one of them for a deeper study, that is the insertion of baked bricks in adobe vaults. In order to consolidate the campaigns: an observation campaign of collapsing houses and laboratory.

The insertion of bake Nevertheless, the authors plaster was partially removed:
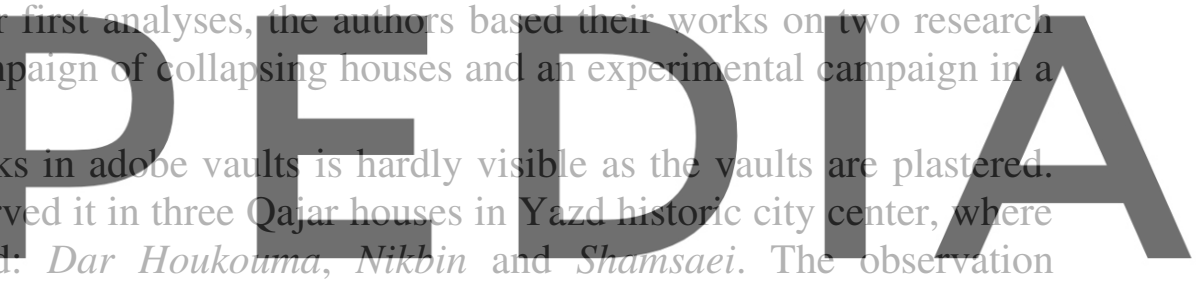
campaign mainly focused on Shamsaei house as its condition allowed for a deeper

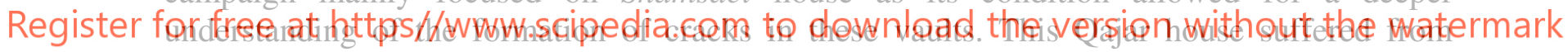
improper maintenance, amongst others related to its roofing plaster, and had been abandonned for a dozen years at the time of the campaign (2016). It was especially interesting as it includes five collapsing or badly cracked vaults built using both adobes and baked bricks. One or two rows of baked bricks were regularly inserted in the barrel adobe vaults, at a distance ranging from $30 \mathrm{~cm}$ to $1 \mathrm{~m}$. Wherever visible, it was noticed that main cracks and partial collapses systematically occurred at the baked bricks rows locations (Figure 4).

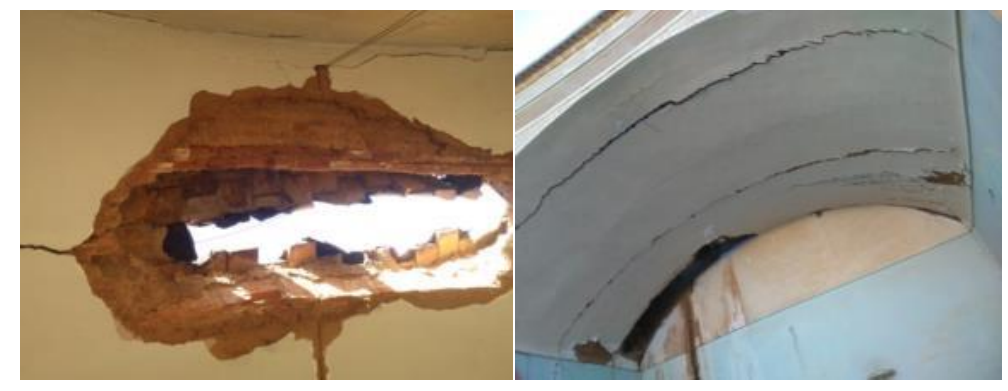

Figure 4: Baked bricks rows in an adobe vault and the creation of sectional cracks, the example of Shamsaei house, Yazd (Crété, 2015) 
This observation campaign confirmed the frequent propagation of cracks at the interface between baked bricks and adobe bricks. An experimental campaign based on the shear strength assessment of brick masonry [25,26,27] was then conducted at 3SR laboratory in order to better understand this phenomenon. The authors first had to determine a composition for the mud mortar they would use for the campaign. They tested several compositions based on clay, sand and fibers. They selected 4 formulas out of 7 thanks to qualitative observations. They then performed shear tests on 8 sandwiches made out of adobe and 4 kinds of mud mortars after complete drying ( 1 month): clay with $20 \%$ fiber by volume of clay (OC20F), clay with $20 \%$ fiber and $10 \%$ sand (OC20F10S), clay with $10 \%$ fiber and $10 \%$ sand (OC10F10S) and clay with 20\% fiber and 20\% sand (OC20F20S). The experimental setup using Schenck press in shown in Figure 5. The average shear stress value ranged from $0.032 \mathrm{Mpa}$ for the OC20F20S mortar to 0.059Mpa for the OC20F10S mortar, which was chosen to perform the next tests.
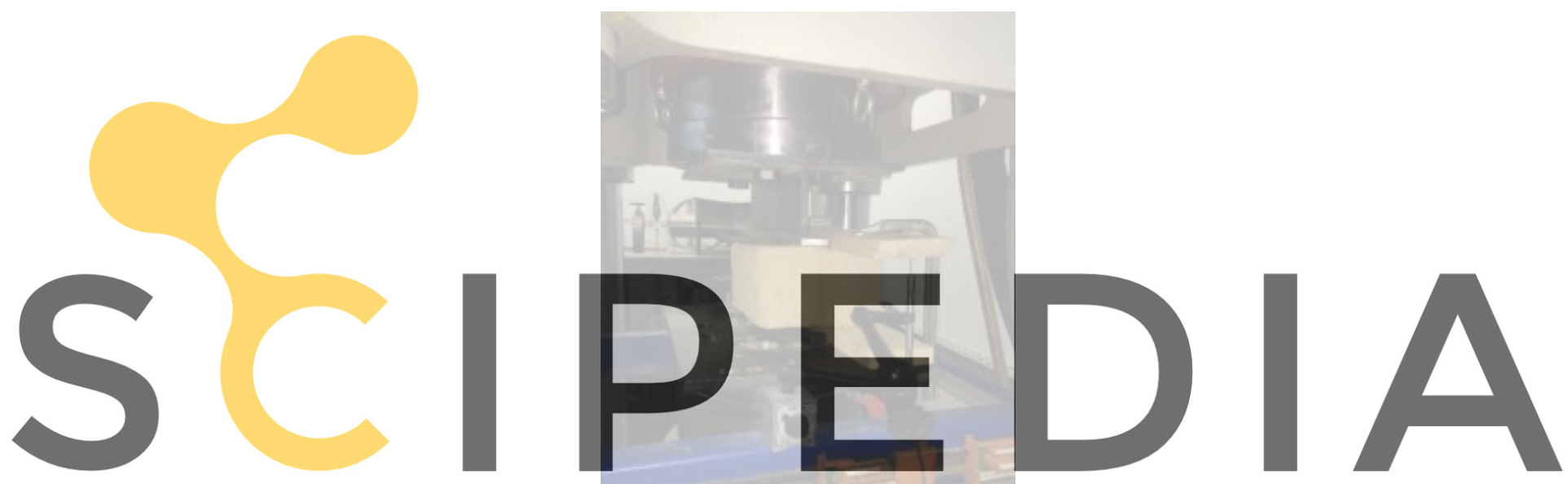

\section{Register for free at https//www.scipedia.com to download the version without the watermark}

Figure 5: The shear stress value of a sandwich sample made out of two adobes and mud mortar is tested with a Schenck press

Once the composition of the mud mortar defined, six sandwich samples were produced to assess their shear stress value: Three samples were made out of baked bricks (samples A, B and C), three out of adobe bricks (samples 1,2 and 3). A main factor of influence on the bond development being the water content of the bricks before mortar laying [28], two samples of each type were prepared by wetting the bricks before applying the mortar (samples A,B, 1 and 2), and one was prepared without wetting the bricks (samples $\mathrm{C}$ and 3 ). The following average shear stresses were measured:

\begin{tabular}{|c|l|l|}
\hline \multirow{2}{*}{ Adobe } & Wet (samples 1,2$)$ & $0.86 \mathrm{MPa} ; 0.130 \mathrm{MPa}$ \\
\cline { 2 - 3 } & Dry (sample 3) & $0.008 \mathrm{MPa}$ \\
\hline \multirow{2}{*}{ Baked bricks } & Wet (samples A, B) & $0.84 \mathrm{MPa} ; 0.145 \mathrm{MPa}$ \\
\cline { 2 - 3 } & Dry (sample C) & $0.055 \mathrm{MPa}$ \\
\hline
\end{tabular}

Table 1: The shear stress values (Mpa) of adobe and baked bricks sandwiches samples 
When wet before mortar application, the shear stress values for both baked and adobe bricks are comparable. They are respectively two times and ten times higher than when samples were prepared without wetting the bricks before the application of mortar. This important decrease in shear resistance may be explained by an improper bond development due to a too fast moisture flow between the bricks and mortars, inducing important shrinkage in the mud mortar as can be seen in Figure 6. This phenomenon could also explain the gap between samples 3 and $\mathrm{C}$, as adobe bricks have higher absorption rate than baked bricks.
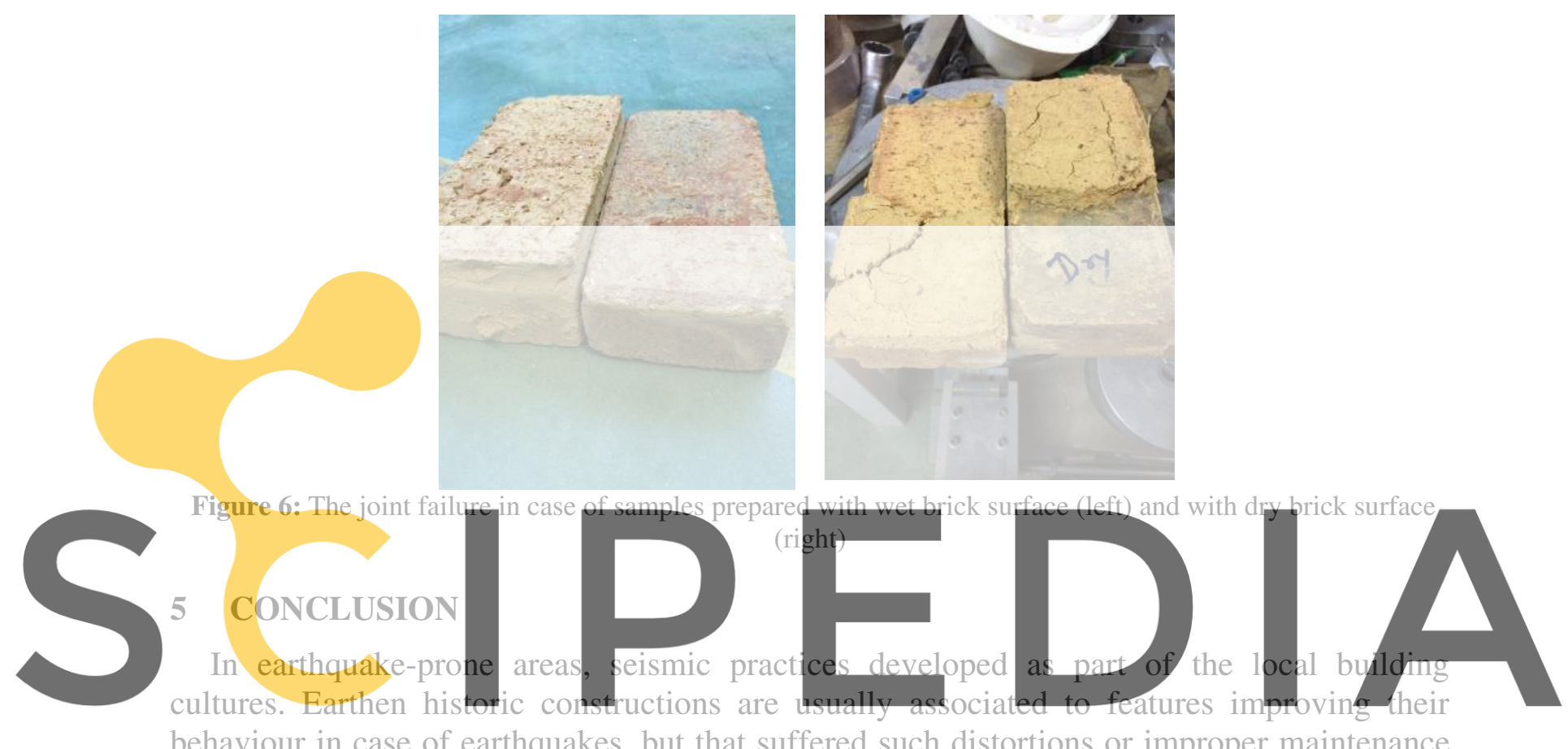

behaviour in case of earthquakes, but that suffered such distortions or improper maintenance

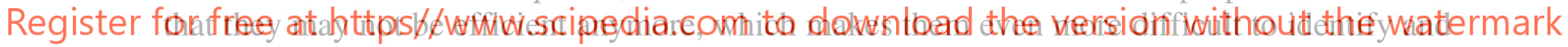
analyse, triggering a vicious circle. The methodology illustrated by Yazdi Qajar architecture study in this paper helped in identifying several features that may be of importance regarding the seismic behaviour of Qajar buildings, amongst other the insertion of baked bricks in adobe vaults. The observation campaign showed that major cracks frequently occurred at the interface between baked bricks and mud mortar in adobe vaults. Further observation campaigns on collapsing Qajar houses in other cities were Qajar architecture is found would confirm if this observation is wide-spread or local. The experimental campaign showed that for the same composition of mud mortar, the shear strength value is similar with baked brick or adobe brick which are prepared by wetting the brick before application of mortar, but that this shear resistance is two times lower if bricks are not wet. Could this be a technic used by traditional masons to create fuse surface that would crack first, thus dissipating energy without endangering the vault stability? To further consolidate this technical assumption, it would be interesting to conduct the same experimental campaign on samples prepared with Yazdi traditional adobes, baked bricks and mud mortar. This could highlight other factors explaining lower bond strengths between baked bricks and mud mortars.

The suggested methodology helped in identifying architectural features that may have developed as part of a local seismic culture but that suffered from distortions or forgetfulness. 
But once these elements identified and understood, complementary research must help understanding why these distortions happened and especially if they were intentional or not. This must be understood before restoration works to decide whether the distorted element should be kept in its adapted version or if it must be corrected to improve the building behaviour in case of seismic solicitations. Intentional distortion may result from an adaptation of the technic to lower seismic areas because another stake was given priority, as noticed for example by Hofmann [1] in relation with the spacing between timber seismic bands in Turkey. In Iran, the reduction of buttresses and the turning of many alcoves into merely aesthetic elements may be an intentional distortion. Further research in more seismic areas where Qajar architecture disseminated would help validating this hypothesis. The unintentional distortions, out of forgetfulness or misunderstanding of the seismic interest of a practice, is closely related to the disruption of traditional knowledge transfer processes that happened mainly from the end of $19^{\text {th }}$ century [1]. Could a datation of the distortion help in sorting out if it is an intentional one or not? And to what extent should we consider that the highest stakes at the time of the construction (for example economical ones), that may have induced intentional distortions, are still consistent nowadays? Keeping in mind that the preservation of cultural heritage falls increasingly into a narrative of continuous evolution and adaptation to current stakes, an approach that may help in building cultural resilience [29].

Whether distorted or not, a deep understanding of these features is of major importance to develop proper maintenance of historic buildings. The loss of knowledge and understanding can induce adverse consequences when they result in the replacement of traditionally used materials by others endanger vernacular with inconsistent mater entail an acceleration runoff concentration, specific zones, salts migration....
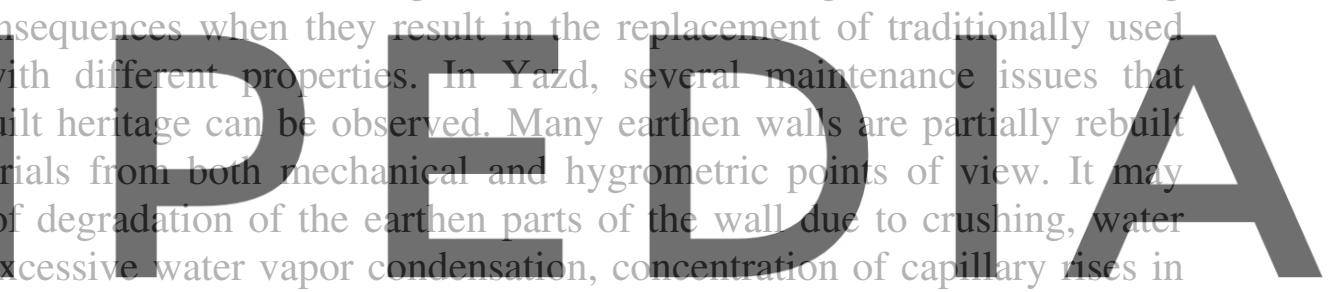

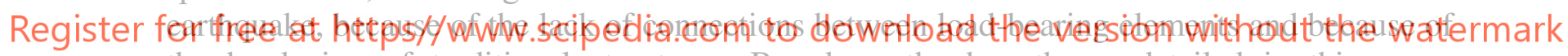

the burdening of traditional structures. Based on the hypotheses detailed in this paper regarding several seismic features of Qajar architecture, several other examples of improper maintenance should be highlighted: for example when changing the traditional mortar by a stronger one in panels whose relative weakness is important. Or in case the mortar is stronger than the bricks, resulting in a propagation of cracks inside bricks and not only inside mortar which no longer induce a delimitation of interlocked blocks. Besides, baked bricks walls are often used to obstruct historic access. These panels may induce severe damage in case of an earthquake because of their relatively high stiffness and because of the lack of good connections with original walls. This discussion on the improper maintenance that can be observed regarding Yazd city center highlights the importance of identifying and understanding these traditional seismic practices.

Moreover, further research is needed to get a deeper understanding of the practices exposed in this paper and further consolidate the assumptions the authors could elaborate, especially regarding the different masonry patterns. Besides, other practices were noticed by the authors, without them being able to conduct further work to develop assumptions about their interest from a seismic point of view. One relates to the high occurrence of empty vertical joints in adobe masonry: Is it mere faulty works, or could it be a way to keep strains 
localized under lateral stresses? A second one relates to muqarnas, that may have developed as a friction damper timber capital (a practice documented in Nepal and Pakistan [17]) when built out of several wooden pieces and not out of a single one as is mostly done nowadays. Finally, the authors would recommend further research regarding the mix of adobes and baked bricks when building windcatchers along with research on their structural behaviour, as the very function of those items induces a need for structural strategies to cope with the vibrations and lateral forces due to winds.

Acknowledgements. This work was conducted in the framework of the LABEX AE\&CC and the IDEX CDP Risk@Univ. Grenoble Alpes as part of the program "Investissements d'Avenir" overseen by the French National Research Agency (reference: ANR-15-IDEX-02).

\section{REFERENCES}

[1] Hofmann, M. Le facteur séisme dans l'architecture vernaculaire. Un décryptage entre déterminants culturels, types de structures et ressources cognitives parasismiques. $\mathrm{PhD}$ thesis. EPFL : EPFL - ENSAG (2015)

[2] Feilden, B.M. Between two earthquakes: cultural property in seismic zones. Rome: Marina del Rey, Calif., USA : ICCROM; Getty Conservation Institute. (1987) 103 p. ISBN 978-0-89236-128-1

[3] Ferrigni, F., European University Centre For The Cultural Heritage (dir.). Ancient buildings and earthquakes: reducing the vulnerability of historical built-up environment by recovering the local seismic culture; principles, methods, potentialities. Bari : Edipuglia. (2005) 360 p. ISBN 978-88-7228-403-2

[4] Modarres, A. Modernizing Yazd: selective historical memory and the fate of vernacular architecture. Costa Mesa, Calif : Mazda Publishers. (2006) 199p. ISBN 978-1-56859140-7

[5] Fallah Aliabadi, S., Sarsangi, A., Modiri, E. « The social and physical vulnerability assessment of old texture against earthquake (case study: Fahadan district in Yazd City) ». In : Arabian Journal of Geosciences [en ligne]. (2015). DOI 10.1007/s12517-0151939-8. Disponible sur : < http://link.springer.com/10.1007/s12517-015-1939-8 > (last accessed on 30 september 2015).

[6] BHRC, Iranian code of practice for seismic resistant design of buildings (Standard No. 2800). Fourth Revision. Tehran, Iran: Building and Housing Research Center, Iran (2015) (in Persian).

[7] Lourenço, P.B., Oliveira D.V., et al. "Simplified indexes for the seismic assessment of masonry buildings: International database and validation". In: Engineering Failure Analysis. (2013) 34:585-605. DOI: 10.1016/j.engfailanal.2013.02.014

[8] Sadeghi, N.H., Oliveira D.V. et al. "Seismic performance of historical vaulted adobe constructions: a numerical case study from Yazd, Iran". In : International Journal of Architectural Heritage (2017). DOI: 10.1080/15583058.2017.1422573

[9] Lourenço, P.B., Greco, F.,et al. Seismic Retrofitting Project - Modeling of Prototype Buildings. Getty Conservation Institute : Los Angeles. (2019) ISBN: 978-1-937433-63-5

[10] Jarpa, T.R. Détermination de la période fondamentale des bâtiments. Proposition d'un outil simplifié à l'usage des architectes. Paris : ENSAPB. (2014) 
[11]Lourenço, P.B., Roque, J.A. « Simplified indexes for the seismic vulnerability of ancient masonry buildings ». In : Construction and Building Materials. (2006). Vol. 20, $\mathrm{n}^{\circ} 4, \mathrm{p}$. 200-208. DOI 10.1016/j.conbuildmat.2005.08.027

[12] Billard, A. Risque sismique et patrimoine bâti: réduction de la vulnérabilité : savoirs et savoir-faire. Paris; La Plaine Saint-Denis : Eyrolles ; AFNOR. (2014) ISBN 978-2-21213613-5.

[13] Gelfi, P. "Role of horizontal backfill pressure on the stability of masonry vaults". In: Internationale Zeitschrift fur Bauinstandsetzen und Baudenkmalpflege. (2002) 8. Jahrang, Heft 6, 573-590

[14]Peyret, N. Dissipation de l'énergie mécanique dans les assemblages : effet du frottement en sollicitation dynamique. PhD Thesis. Paris : Université Paris-Est (2012)

[15] Crete, E., Yadav S. et al. "Timber seismic bands: correlating their characteristics with local seismic activities and understanding their effects under seismic loads". In : AntiSeismic Vernacular Heritage of Anatolia and Beyond. Istanbul : ICOMOS ISCARSAH Turkey. (2018) ISBN: 978-605-245-789-4

[16] Yadav, S., Sieffert, Y., Crete, E., Vieux-Champagne, F., Garnier, P. "Mechanical behaviour of different type of shear band connections being used in reconstruction housing in Nepal". In : Construction and Building Materials, Elsevier, (2018) 174, pp.701-712. 〈10.1016/j.conbuildmat.2018.04.121〉. 〈hal-01780074〉

[17] Caimi, A., Moles, O., Crete, E. Local building cultures for resilience and development Examples of local good practices and technical solutions. Villefontaine : CRAterre. (2017) ISBN 979-10-96446-13-1

[18] Shakouri, R. Habitat résidentiel durable en Iran - savoirs-faire traditionnels et technologies nouvelles à Yazd. PhD thesis. Grenoble : Pierre Mendes France. (2008)

[19] Arbabian, H. «Architectural Issues in Earthquake Rehabilitation of the Iranian Cultural Heritage | CICOP Italia ». In : [on line] < https://www.cicop.it/wordpress/en/pubblications-articles/architectural-issues/> (2002) (last accessed on 20 December 2019).

[20] Maini, S. Diagnostic of damages to vaulted structures Arg-e-Bam and Bam area, Iran. Auroville : Auroville Earth Institute (2004)

[21] Joffroy, T., Moriset, S., Hajmirbaba, M., Gandreau, D. Bam, Iran - Final report. (2006)

[22] Bolorizadeh, M. The Secrets to Earthquake Resistance of Mud-brick Structures in Bam, After 2004 Earthquake, with a Methodological Approach. Yazd : Faculté d'Architecture de Yazd (2015)

[23] Deghan, M., Laboratoty analysis of Yazd clay based on swelling potential and mineral components. Tehran : Faculty of civil engineering, University Amir Kebir (2003) (in Persian)

[24] Hejazi, M., Saradj, F. M. Persian Architectural Heritage: Architecture, Structure and Conservation. Southampton : WIT Press. (2014) 527 p. ISBN 978-1-78466-070-3.

[25]Dhanasekar, M., Kleeman, P. W., Page, A. W.: Biaxial Stress-strain Relations for Brick Masonry. In: Journal of Structural Engineering (ASCE), v. 111, n. 5 (1985). https://doi.org/10.1061/(asce)0733-9445(1985)111:5(1085)

[26] Alecci, V., Fagone, M., Rotunno, T., \& De Stefano, M.. Shear strength of brick masonry walls assembled with different types of mortar. Construction and Building Materials, 40, 1038-1045. https://doi.org/10.1016/j.conbuildmat.2012.11.107 (2013) 
[27] Ali, Q., Badrashi, Y. I., Ahmad, N., Alam, B., Rehman, S., \& Banori, F. A. S.. Experimental investigation on the characterization of solid clay brick masonry for lateral shear strength evaluation. International Journal of Earth Sciences and Engineering, 05(04). (2012)

[28] Groot, C. J. W. P., Effects of water on mortar brick bond. PhD thesis, University of Delft, Delft, The Netherlands (1993)

[29]Holtorf, C., Enhancing cultural resilience by learning to appreciate change and transformation, in: Humanistic futures of learning - Perspectives from UNESCO Chairs and UNITWIN Networks. Paris: UNESCO (2020). ISBN 978-92-3-100369-1 